\title{
Occupational level of the father and alcohol consumption during adolescence; patterns and predictors
}

\author{
M Droomers, C T M Schrijivers, S Casswell, J P Mackenbach
}

J Epidemiol Community Health 2003;57:704-710

\begin{abstract}
Study objective: This paper describes and attempts to explain the association between occupational level of the father and high alcohol consumption among a cohort of New Zealand adolescents from age 11 to 21 .

Design: Data were obtained from the longitudinal Dunedin multidisciplinary health and development study. At each measurement wave, those who then belonged to the quartile that reported the highest usual amount of alcohol consumed on a typical drinking occasion were categorised as high alcohol consumers. Potential predictors of high alcohol consumption included environmental factors, individual factors, and educational achievement measured at age 9, 11, or 13. Longitudinal logistic GEE analyses described and explained the relation between father's occupation and adolescent alcohol consumption.

Setting: Dunedin, New Zealand.

Participants: About 1000 children were followed up from birth in 1972 until adulthood.

Main results: A significant association between fathers' occupation and adolescent alcohol consumption emerged at age 15. Overall adolescents from the lowest occupational group had almost twice the odds of being a large consumer than the highest occupational group. The association between father's occupation and high alcohol consumption during adolescence was explained by the higher prevalence of familial alcohol problems and friends approving of alcohol consumption, lower intelligence scores, and lower parental attachment among adolescents from lower occupational groups.

Conclusions: Socioeconomic background affects adolescent alcohol consumption substantially. This probably contributes to cumulation of disadvantage. Prevention programmes should focus on adolescents from lower socioeconomic groups and make healthier choices the easier choices by means of environmental change.
\end{abstract}

See end of article for authors' affiliations

Correspondence to: Mariël'Droomers, RIVM/PZO, Interne Postbak 84, PO Box 1, 3720 BA Bilthoven, Netherlands; mariel.droomers@rivm.nl

Accepted for publication 26 February 2003
S ocioeconomic differences in unhealthy behaviour, such as excessive consumption of alcohol ${ }^{1-4}$ are one of the main pathways by which socioeconomic health differences develop. $^{5-7}$ Attempts to explain socioeconomic differences in unhealthy behaviour have mainly focused on adults, while lifestyle patterns are largely developed and perpetuated during adolescence. Not much is known about the development of socioeconomic differences in unhealthy lifestyles during adolescence and even less about the determinants of this process. Such information, however, would facilitate the design of effective interventions to tackle the development of socioeconomic differences in behaviour at an early stage.

The objective of this paper is to study patterns and predictors of socioeconomic differences in adolescents' alcohol consumption. The longitudinal Dunedin multidisciplinary health and development study followed up a birth cohort of about 1000 individuals during their entire adolescence and hence provides the unique opportunity to describe and explain the relation between fathers' occupation and high alcohol consumption.

Literature review shows that adolescents of low socioeconomic backgrounds tend to consume more alcohol and consume alcohol more often than peers from higher socioeconomic groups do, ${ }^{8-12}$ although there are also studies that could not corroborate such a relation. ${ }^{13-18}$ Some of this inconsistency in the literature might be attributable to the failure to adequately conceptualise different dimensions of alcohol consumption, and in particular, to distinguish between frequency of consumption and quantities consumed. ${ }^{19}$

The association between parental socioeconomic status and adolescents' alcohol consumption might be explained by a higher prevalence of predictors of high alcohol consumption in lower socioeconomic groups compared with peers from higher socioeconomic backgrounds (fig 1). To date not many predictors of adolescents' alcohol consumption have been investigated for their relation with socioeconomic status and only rare studies have studied their contribution to the explanation of socioeconomic differences in high alcohol consumption.

Predictors of high adolescent alcohol consumption described by the literature can be roughly divided into environmental and individual factors. Important social environmental predictors derive from family socialisation processes, such as modelling, supervision, norms, and relationships. Adolescents whose parents drink alcohol are more inclined to drink themselves. ${ }^{12}{ }^{16} 20-30$ Other familial processes that increase adolescents' alcohol consumption are inadequate parenting practices, ${ }^{21} 232431$ poor parental monitoring and control, ${ }^{13} 242632$ poor parental support, ${ }^{8232}$ poor family cohesion or bonding, ${ }^{15} 212533$ positive parental norms or tolerance of alcohol consumption, ${ }^{14} 20-222425282934$ and familial alcohol problems or alcoholism. ${ }^{93133} 35$

Having friends that drink alcohol also increases the risk of high alcohol consumption, ${ }^{13} 1418$ 20-22 28-30 $333^{34} 36-38$ as well as pressure or encouragement of friends to drink, ${ }^{14}{ }^{152}$ friends with positive norms concerning alcohol, ${ }^{14} 202938$ and even the idea that most peers drink alcohol. 22837

In general, material environmental factors are considered important explanations for socioeconomic differences in health or related behaviour. ${ }^{5-7}$ Material factors, like financial strains or material deprivation reduce alcohol consumption during adolescence. ${ }^{29} 35$

Individual characteristics that predict high adolescents' alcohol consumption are low self regulation, 22 233039 low self 


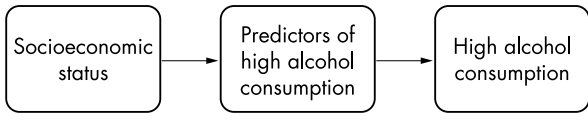

Figure 1 Conceptual model

esteem, ${ }^{23}{ }^{36}$ tolerance for deviance, ${ }^{30} 313638$ risky behaviour, ${ }^{31} 3639$ anti-social behaviour-that is, aggressiveness, hyperactivity, or neuroticism, ${ }^{21}$-and a positive attitude towards alcohol. $^{142129}$ Adolescents who score lower on academic competence, $^{23}$ academic expectations, ${ }^{14}{ }^{16}$ educational commitment, ${ }^{21}{ }^{33}$ or who experience academic failure ${ }^{1416212234}$ also reported to drink more alcohol.

\section{METHODS \\ Population}

Data were obtained from the Dunedin multidisciplinary health and development study, which follows up the health and behaviour of a cohort of children from birth until adulthood. ${ }^{40}$ The sample consists of a cohort born in Dunedin's only obstetric hospital between 1 April 1972 and 31 March 1973. The perinatal histories were recorded soon after birth, but study members were first enrolled at age 3. Ninety one per cent of eligible births (that is, still resident in the province of Otago) participated in this first assessment, providing a base sample of 1037 for the longitudinal study. Study members were further assessed every two years thereafter, up to and including age 15 and again at age 18,21, and 26. Transportation to the research unit was provided for those living in New Zealand, but outside of Dunedin, to maximise the number of the study members being assessed in full. In the case of study members living overseas, an interviewer travelled to these locations (almost all of them were in Australia). This procedure resulted in very high follow up rates-that is, from $90 \%$ to $97 \%$ of the study members included in the baseline sample-with a one time low follow up rate of $82 \%$ at age $13 .^{40}$ Before the interviews informed consent was obtained either from a parent (for interview prior to age 18) or from the participant starting at age 15. For more detailed information on the Dunedin study we refer to earlier publications. ${ }^{40}$

The sample was representative of the population of New Zealand's South Island and was primarily of European descent. ${ }^{40}$

\section{Measures}

Amount of alcohol was represented by the study member's average amount consumed on a typical occasion. The answer to the question "How much do you usually have to drink?" in a number of different drinking contexts, together with information on the type of alcohol and the size of the glass, was converted into millilitres of absolute alcohol usually drunk. At each measurement wave, we categorised those adolescents who belonged to the quartile $(25 \%)$ that reported the highest usual amounts as drinkers of comparatively large amounts of alcohol. The amount of alcohol usually consumed ranged from $0-31 \mathrm{ml}$ at age 11 (highest quartile $4-31 \mathrm{ml}$ ), 0-70 $\mathrm{ml}$ at age 13 (highest quartile $8-70 \mathrm{ml}$ ), $0-555 \mathrm{ml}$ at age 15 (highest quartile $(51-555 \mathrm{ml}), 0-1072 \mathrm{ml}$ at age 18 (highest quartile 130-1072 ml), and from 0-991 $\mathrm{ml}$ at age 21 (highest quartile 236-991 ml). Frequency of alcohol consumption was assessed by the average number of occasions alcohol was consumed during a certain period of time. At age 11 and 13, the interviews on alcohol consumption were carried out in private at the research unit by the same trained interviewer. Study members who were not able to attend the research unit for assessment were not administered the questionnaire about alcohol. At age 15, 18, and 21, questions about alcohol were included in the home, school, or workplace interviews. One interviewer carried out most of these interviews.

Occupational level of the father was measured at the beginning of adolescence, at age 9 , and categorised according to the
Elley-Irving classification. This classification is specially designed for use in New Zealand, but internationally comparable to other occupational classifications, because it is based on the International Standard Classification of Occupations (ISCO).${ }^{41}$ Average income and education levels (based on the 1981 New Zealand census for males) were used to rate the fathers' occupations. ${ }^{42}$ When information on occupational level of the father was missing, information collected at later measurements (until age 15) was used. Because of low numbers, we combined the two lowest occupational categoriesthat is, semi-skilled and unskilled.

The Dunedin multidisciplinary health and development study assessed several potential predictors of alcohol consumption among adolescents, like social and material environmental factors, individual factors and achievement (table 1). Reliable and validated questionnaires were used whenever available (table 1). To enable identification of risk groups, we divided all continuous scale variables into tertiles (for example, parental attachment or intelligence).

\section{Analyses}

The statistical testing of the conceptual model (fig l) was undertaken in four stages. In the first stage we studied the relation between occupation of the father and high alcohol consumption. We fitted logistic regression models, adjusted for sex, with the highest occupational group as a reference category, for each measurement wave separately. Next, we fitted a logistic generalised estimating equation (GEE) model that takes into account the dependence between repeated measurements within the same individual, using the GENMOD procedure of SAS 8.0..$^{2}$ We calculated occupational differences in large amounts of alcohol consumption in the period from age 11 to 21 with a GEE model including sex, time, and occupation of the father.

At the second stage, we studied which variables longitudinally predicted high alcohol consumption in the period from age 11 to 21 , by fitting GEE models containing sex, time, and one potential determinant successively. Variables were considered predictors of alcohol consumption when the GEE analyses showed significant $\chi^{2}$ likelihood ratio test $(p<0.05)$ and at least one significantly increased odds ratio.

At the third stage, for those predictors that showed significantly increased odds of drinking large amounts of alcohol, we studied the distribution of categories of the predictor by occupational level of the father.

Finally, at stage 4, we added significant predictors of alcohol consumption that were related to occupational level of the father, to the first GEE model (including sex, time, and occupation) in an attempt to explain the association between fathers' occupation and drinking large amounts of alcohol consumption. The contribution of the predictor to the explanation of differences in alcohol consumption was expressed by the percentage reduction in significantly increased odds ratios of the different occupational groups (all significantly increased odds ratios of occupation of the father should decrease their value due to inclusion of predictor).

\section{RESULTS}

\section{Stage 1}

In this New Zealand cohort of adolescents, we found no relation between father's occupation and frequency of alcohol consumption among adolescents (results not shown). Significant cross sectional occupational differences in drinking larger amounts of alcohol emerged when the adolescents were aged 15 years (table 2). Adolescents from the lowest occupational groups, aged 15 years or older, had odds of about 2.5 times higher than the highest occupational groups to drink larger amounts of alcohol.

Longitudinal GEE analyses that take into account the whole adolescent period from age 11 until 21 confirmed a 
Table 1 Measurement of potential predictors of drinking large amounts of alcohol among adolescents

\begin{tabular}{|c|c|c|c|c|c|}
\hline Predictor & Reported by & Age & Items & Answer categories & Reference \\
\hline \multicolumn{6}{|l|}{ Social environmental factors } \\
\hline Alcohol consumption mother & adolescent & 9 & 1 & yes/no & \\
\hline Alcohol consumption father & adolescent & 9 & 1 & yes/no & \\
\hline Alcohol problems in family noticeable to adolescent & parent & 9 & 1 & yes/no & \\
\hline Alcohol consumption friends & adolescent & 11 & 1 & yes/no & \\
\hline Attitude towards alcohol consumption in general in six different situations & parent & 9 & 6 & perfectly all right/usually all right/sometimes all right/never all right & \\
\hline Mother's attitude towards alcohol consumption adolescent & adolescent & 11 & 1 & strongly approves/approves/does not $\mathrm{mind} /$ disapproves/strongly disapproves & \\
\hline Father's attitude towards alcohol consumption adolescent & adolescent & 11 & 1 & strongly approves/approves/does not mind/disapproves/strongly disapproves & \\
\hline Friends' attitude towards alcohol consumption adolescent & adolescent & 11 & 1 & strongly approves/approves/does not $\mathrm{mind} /$ disapproves/strongly disapproves & \\
\hline Have your parents told you anything about alcohol & adolescent & 11 & 1 & negative/neutral/positive/nothing & \\
\hline Has school told you anything about alcohol & adolescent & 11 & 1 & yes/no & \\
\hline Family relationships & parent & 9 & 27 & true/false & 43,44 \\
\hline Attachment to parents & adolescent & 13 & 12 & (almost) never/sometimes/often/(almost) always & 45 \\
\hline Attachment to friends & adolescent & 13 & 12 & (almost) never/sometimes/often/(almost) always & 45 \\
\hline I belong to organised groups, clubs or activities & adolescent & 11 & 1 & yes/no & \\
\hline Recalled number of pro-alcohol messages in media & adolescent & 13 & 1 & any number & \\
\hline \multicolumn{6}{|l|}{ Material environmental factors } \\
\hline Child receives pocket money & parent & 11 & 1 & yes/no & \\
\hline Number of children in family & parent & 11 & 1 & number of children & \\
\hline Unemployment of the father in the past two years & parent & 13 & 1 & yes/no & \\
\hline \multicolumn{6}{|l|}{ Individual factors } \\
\hline Self esteem & adolescent & 11 & 10 & strongly agree/agree/disagree/strongly disagree & 46 \\
\hline Fearfulness & parent & 11 & 5 & doesn't apply/applies somewhat/certainly applies & 47 \\
\hline Health locus of control & adolescent & 13 & 6 & strongly disagree/disagree/agree/strongly agree & 48,49 \\
\hline Behavioural problems & parent & 11 & 77 & doesn't apply/applies somewhat/certainly applies & 50 \\
\hline Attitude towards alcohol consumption & adolescent & 11 & 3 & strongly agree/agree little/disagree little/strongly disagree & \\
\hline Attitude towards drunkenness & adolescent & 11 & 7 & strongly agree/agree little/disagree little/strongly disagree & \\
\hline \multicolumn{6}{|l|}{ Achievement } \\
\hline Performance at school & parent & 11 & 1 & average/below average/above average & \\
\hline Intelligence (IQ) & adolescent & 11 & & Wechsler Intelligence Scale for Children & 51 \\
\hline
\end{tabular}


Table 2 Association between occupational level of the father and drinking large amounts of alcohol during adolescence

\begin{tabular}{|c|c|c|c|c|c|c|}
\hline & \multicolumn{5}{|l|}{ Age } & \multirow{2}{*}{$\begin{array}{l}\text { Longitudinal GEE } \\
\text { adolescent period OR† }\end{array}$} \\
\hline & $11 \mathrm{OR}^{*}$ & $13 \mathrm{OR}^{*}$ & $15 \mathrm{OR}^{*}$ & $18 \mathrm{OR}^{*}$ & $21 \mathrm{OR}^{*}$ & \\
\hline \multicolumn{7}{|l|}{ Occupational level of father (frequency) } \\
\hline higher professional, administrative (14\%) & 1.00 & 1.00 & 1.00 & 1.00 & 1.00 & 1.00 \\
\hline lower professional, technical (14\%) & 1.39 & 1.04 & 1.70 & 1.42 & 1.46 & $1.37(0.97$ to 1.93$)$ \\
\hline clerical, highly skilled (26\%) & 0.84 & 0.83 & 1.50 & $1.98 \S$ & 1.67 & 1.26 (0.92 to 1.73$)$ \\
\hline skilled $(29 \%)$ & 0.82 & 0.91 & 1.51 & $2.15 \S$ & $1.89 \S$ & 1.34 (0.99 to 1.82$)$ \\
\hline semi-skilled, unskilled (17\%) & 1.02 & 1.40 & $2.80 \S$ & $2.17 \S$ & $2.49 \S$ & 1.85 (1.32 to 2.60$)$ \\
\hline$p$ valuef & 0.3006 & 0.3804 & 0.0202 & 0.0139 & 0.0533 & 0.0106 \\
\hline Number of study members assessed & 925 & 850 & 976 & 993 & 992 & \\
\hline Number of study members interviewed on alcohol & 794 & 734 & 844 & 915 & 900 & \\
\hline
\end{tabular}

statistically significant association between fathers' occupational status and high alcohol consumption (table 2). Considering this whole period, adolescents from the lowest occupational group had almost twice the odds of being a large consumer than the highest occupational group (table 2). Occupational differences in alcohol consumption significantly increased during this period (p value occupation $\times$ phase $=0.0302$ ). This confirmed the cross sectional finding that occupational differences in alcohol consumption in this New Zealand cohort developed only at a later stage during adolescence.

\section{Stage 2}

Table 3 shows statistically significant predictors of high alcohol consumption during adolescence. None of the material or individual factors predicted high alcohol consumption. Several social environmental factors, however, did predict high alcohol consumption. Adolescents that felt that their mother or friends did not mind, or approved of them

Table 3 Predictors of drinking large amounts of alcohol during adolescence

\begin{tabular}{|c|c|c|}
\hline & $\mathrm{OR}^{*}$ & $\mathrm{p}$ value \\
\hline \multicolumn{3}{|l|}{ Social environmental factors } \\
\hline Mother's attitude towards alcohol consumption child & & 0.0425 \\
\hline strongly disapprove & 1.00 & \\
\hline disapprove & 1.17 & \\
\hline does not mind & $1.40 \ddagger$ & \\
\hline (strongly) approves & 1.44 & \\
\hline \multicolumn{2}{|l|}{ Friends' attitude towards alcohol consumption } & 0.0407 \\
\hline strongly disapprove & 1.00 & \\
\hline disapprove & 1.07 & \\
\hline does not mind & $1.35 \ddagger$ & \\
\hline (strongly) approves & $1.46 \ddagger$ & \\
\hline \multicolumn{2}{|l|}{ Noticeable alcohol problems in family } & 0.0341 \\
\hline no & 1.00 & \\
\hline yes & $1.29 \ddagger$ & \\
\hline \multicolumn{2}{|l|}{ Have your parents told you anything about alcohol } & 0.0216 \\
\hline negative messages & 1.00 & \\
\hline neutral/positive messages & $1.36 \ddagger$ & \\
\hline nothing & 1.21 & \\
\hline & 0.0012 \\
\hline high attachment & 1.00 & \\
\hline medium attachment & $1.42 \ddagger$ & \\
\hline low attachment & $1.50 \ddagger$ & \\
\hline \multicolumn{3}{|l|}{ Achievement factors } \\
\hline \multicolumn{2}{|l|}{ Intelligence } & 0.0053 \\
\hline higher intelligence scores & 1.00 & \\
\hline medium intelligence scores & 1.12 & \\
\hline lower intelligence scores & $1.42 \ddagger$ & \\
\hline \multicolumn{3}{|c|}{$\begin{array}{l}{ }^{*} \text { Odds ratio of GEE analyses including ages } 11 \text { to } 21 \text { adjusted for } \\
\text { sex. } t p \text { value of }-2 \text { log likelihood ratio } \chi^{2} \text { test of the predictor. } ¥ 1.00 \\
\text { is not included in } 95 \% \text { confidence intervals of odds ratio. }\end{array}$} \\
\hline
\end{tabular}

drinking alcohol, drank large amounts of alcohol more often. Adolescents who reported having talked about alcohol in a neutral or positive way with their parents were more likely to drink large amounts of alcohol compared with their peers who got negative messages or were not informed about alcohol at all. When parents reported noticeable alcohol problems within the family, their children were significantly more likely to consume large amounts of alcohol. Adolescents who experienced medium or low levels of attachment to their parents drank large amounts of alcohol more often compared with peers who experienced high levels of attachment to their parents. Next to these social determinants of alcohol consumption, also lower intelligence scores significantly predicted high alcohol consumption.

\section{Stage 3}

We studied the relation between occupational level of the father and predictors of large amounts of alcohol consumption using cross tabulations (not tabulated). Only lower intelligence scores were clearly inversely related to fathers' occupational level, whereas a few other predictors were more prevalent only in the lowest occupational group with no clear differences between the other groups - that is, friends approving of alcohol consumption, familial alcohol problems, and medium parental attachment.

\section{Stage 4}

Table 4 shows the predictors of high alcohol consumption that contributed to the explanation of the relation between occupational level of the father and high alcohol consumption. The occurrence of noticeable alcohol problems in the family explained almost $40 \%$ of the increased odds ratio for high alcohol consumption in offspring of the lowest occupational group. The higher prevalence of friends approving of alcohol, lower intelligence scores, and lower parental attachment in the lowest occupational group each explained about $20 \%$. The four predictors together explained $60 \%$ of the significantly increased odds of high alcohol consumption in adolescents from the lowest occupational group, reducing it to nonsignificance.

\section{DISCUSSION}

The longitudinal Dunedin multidisciplinary health and development study on a birth cohort of about 1000 New Zealand children provided the unique opportunity to study possible explanations for socioeconomic differences in alcohol consumption during adolescence. Our results are among the first that combine the description of socioeconomic differences in health related behaviour with an analyses of explanations for this association. We report that adolescents from lower occupational backgrounds more often drink larger amounts of alcohol, because they more often experience familial alcohol 


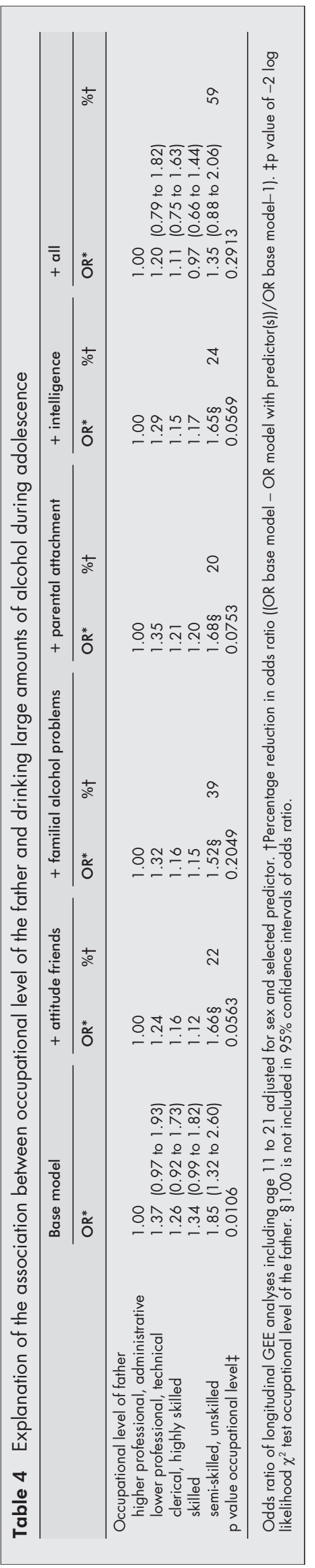

problems, have friends who approve of alcohol consumption, have lower intelligence scores, and report lower parental attachment.

These New Zealand findings on explanations for occupational differences in high alcohol consumption apply probably to other adolescent populations as well, because we report comparable associations between parental socioeconomic status and adolescent alcohol consumption, ${ }^{8-12}$ as well as comparable predictors of high alcohol consumption to other studies. ${ }^{14} 20-2325293334$

Before further elaboration on our results, we discuss methodological issues. Firstly, occupation of the father indicated socioeconomic status of the adolescent, in accordance to many other studies on socioeconomic differences during adolescence. ${ }^{11}{ }^{15-17}$ One objection against occupational level indicating socioeconomic status is the possible variability over time. The correlation $(r>0.7, \mathrm{p}=0.000)$ between the four measurements of occupational level in this study (that is, from age 9 to 15) indicates that occupational ranking was fairly stable during the period studied. Secondly, to exclude all possible concerns about causality between predictors and alcohol consumption, we have chosen to include variables measured before or at age 13-that is, measured in the beginning of our longitudinal analyses. Some variables might have changed after the measurement at baseline, resulting in inaccurate estimations of the effect of these factors on adolescent alcohol consumption. This might apply specifically to factors with a comparatively short-term effect, as we considered a rather long period in our analyses. For example, we failed to find an effect of pocket money on high alcohol consumption, while cross sectional analyses on the present cohort found that at age 15, having more money to spend was associated with drinking larger amounts. ${ }^{53}$ Thirdly, alcohol consumption was self reported, which might have resulted in underestimation of the amount of alcohol consumed. We, however, believe that this does not substantially interfere with the relative rank of study members and hence the classification in the group drinking large amounts of alcohol. ${ }^{54}$

Half of the explanation for the association between fathers' occupational level and drinking large amounts of alcohol relates to the adolescents' family situation-that is, parental attachment and familial alcohol problems. The latter might relate to the contribution of genetic factors to the development of alcohol consumption patterns. ${ }^{91} 36$ Otherwise, both generations might face similar social environments, not captured by variables available in the described analyses, and therefore lower socioeconomic adolescents are likely to drink more, irrespective of the actual drinking behaviour of their parents, because alcohol consumption serves certain purposes in these particular environments. ${ }^{7}$

The lower level of intelligence of children from fathers with a lower occupational level also explained part of their higher alcohol consumption. Similarly, Wills et al found that academic competence explained part of socioeconomic differences in substance use during adolescence. ${ }^{18}$ Less intelligent adolescents might use alcohol consumption to counterbalance their lower academic success. ${ }^{36}$ Alternatively, adolescents with lower IQ scores might be ready to assume adult roles and behaviour earlier, because lower intelligence in itself decreases the opportunity to continue schooling and achieve higher occupational status.

Intelligence is likely to result not only from heredity, but from environmental influences as well. ${ }^{75-58}$ Reviews on long term effects of early childhood education and day care have found persistent positive effects on academic achievement, ${ }^{59} 60$ future socioeconomic status, ${ }^{60}$ as well as sometimes on IQ. ${ }^{55860}$ Greater access to such facilities for lower socioeconomic groups might prevent high alcohol consumption. 
Intervention programmes that aim to prevent high alcohol consumption should be designed appropriately for adolescents from lower socioeconomic backgrounds, as they are disproportionately exposed to potent predictors of high alcohol consumption.

It seems important for interventions to include the social environment of adolescents - that is, help parents with possible alcohol problems take into account the low parental attachment or try to improve it, and attempt to diminish positive attitudes towards excessive alcohol consumption among youth. The latter might be achieved by developing school based interventions, for example in lower socioeconomic neighbourhoods.

\section{ACKNOWLEDGEMENTS}

The Van Walree Foundation and Netherlands Organisation for Scientific Research (NWO) financially supported the working visit of Mariël Droomers to the Alcohol and Public Health Research Unit of the University of Auckland in New Zealand. I want to thank Karen Witten and Philippa Howden-Chapman for providing me the opportunity to come to and work in New Zealand. I greatly esteem the (moral) support I have received from the staff of the Alcohol and Public Health Research Unit during my stay in Auckland. Furthermore, the authors would like to thank Richie Poulton and Barry Milne for their indispensable help in accessing the Dunedin data, and Megan Pledger, Elisabeth Robinson, and Gerard Borsboom for their advice in statistical matters.

\section{Authors' affiliations}

M Droomers, C T M Schrijvers, J P Mackenbach, Department of Public

Health, Erasmus University Rotterdam, Netherlands

S Casswell, APHRU, Auckland University, New Zealand

Conflicts of interest: none.

\section{REFERENCES}

1 Crum RM, Helzer JE, Anthony JC. Level of education and alcohol abuse and dependence in adulthood: a further inquiry. Am J Public Health 1993;83:830-7

2 Droomers, M, Schrijvers CTM, Stronks K, et al. Educational differences in excessive alcohol consumption: the role of psychosocial and material stressors. Prev Med 1999;29:1-10.

3 Midanik, LT, Room R. The epidemiology of alcohol consumption. Alcohol Health Res World 1992;16:183-90

4 Russell M, Cooper ML, Frone MR. The influence of sociodemographic characteristics on familial alcohol problems: data from a community sample. Alcohol Clin Exp Res 1990;14:221-6.

5 Davey Smith G, Blane D, Bartely M. Explanations for socio-economic differentials in mortality. Evidence form Britain and elsewhere. Eur J Public Health 1994;4:131-44.

6 Schrijvers CTM, Stronks K, van de Mheen HD, et al. Explaining educational differences in mortality: the role of behavioral and material factors. Am J Public Health 1999;89:535-40.

7 Townsend P, Davidson N. The Black Report. In: Townsend P, Davidson $\mathrm{N}$, Whitehead M, eds. Inequalities in health. London: Penguin, 1988.

8 Cooper ML, Peirce RS, Tidwell M-CO. Parental drinking problems and adolescent offspring substance use: moderating effects of demographic and familial factors. Psychol Addict Behav 1995;9:36-52.

9 Ellis DA, Zucker RA, Fitzgerald HE. The role of family influences in development and risk. Alcohol Health Res World 1997;21:218-26.

10 Lowry R, Kann L, Collins JL, et al. The effect of socioeconomic status on chronic disease risk behaviours among US adolescents. JAMA 1996;276:792-7.

11 Parker DA, Parker ES. Status and status inconsistency of parents on alcohol consumption of teenage children. Int J Addict 1980;15:1233-9.

12 Wills TA, Pierce JP, Evans RI. Large-scale environmental risk factor for substance use. Am Behav Scientist 1996;39:808-22.

13 Barnes GM, Farrell MP, Banerjee S. Family influences on alcohol abuse and other problem behaviors among black and white adolescents in a general population sample. In: Boyd GM, Howard J, Zucker RA. Alcoho problems among adolescents. Current directions in prevention research. Hillsdale, NJ: Lawrence Erlbaum, 1995

14 Donovan JE, Jessor R. Adolescent problem drinking. Psychosocial correlates in a National sample study. J Stud Alcohol 1978;39:150624.

15 Duncan TE, Duncan SC, Hops $\mathrm{H}$. The effects of family cohesiveness and peer encouragement on the development of adolescent alcohol use: a cohort-sequential approach to the analysis of longitudinal data. J Stud Alcohol 1994;55:588-99.

16 Green G, Macintyre S, West P, et al. Like parent, like child? Associations between drinking and smoking behaviour of parents and their children. Br J Addict 1991;86:745-58.
17 Tuinstra J, Groothoff JW, van den Heuvel WJA, et al. Socioeconomic differences in health risk behaviour in adolescence: do they exist? Soc Sci Med 1998;47:67-74

18 Wills TA, McNamara G, Vaccaro D. Parental education related to adolescent stress-coping and substance use: development of a mediational model. Health Psychol 1995;14:464-78.

19 Casswell S, Pratap S, Pledger M. Trajectories of drinking from 18 to 26 : identification and prediction. Addiction 2002;97:1427-37.

20 Ary DV, Tildesley $E$, Hops $\mathrm{H}$, et al. The influence of parent, sibling, and peer modelling and attitudes on adolescent use of alcohol. Int J Addict 1993;28:853-80.

21 Hawkins JD, Catalano RF, Miller JY. Risk and protective factors for alcohol and other drug problems in adolescence and early adulthood: implications for substance abuse prevention. Psychol Bull 1992;1 12:64-105

22 Jackson C. Initial and experimental stages of tobacco and alcohol use during late childhood: relation to peer, parent, and personal risk factors. Addict Behav 1997;22:685-98.

23 Jackson C, Henriksen L, Dickinson D, et al. The early use of alcohol and tobacco: its relation to children's competence and parents' behavior. Am J Public Health 1997;87:359-64.

24 Jackson C, Henriksen L, Dickinson D. Alcohol-specific socialization, parenting behaviors and alcohol use by children. J Stud Alcohol 1999;60:362-7.

25 Johnson VJ, Pandina RJ. Effects of the family environment on adolescent substance use, delinquency, and coping styles. Am J Drug Alcohol Abuse $1991 ; 17: 71-88$

26 Peterson PL, Hawkins JD, Abbott RD, et al. Disentangling the effects of parental drinking, family management, and parental alcohol norms on current drinking by black and white adolescents. J Res Adol 1994;4:203-27.

27 White HR, Johnson V, Buyske S. Parental modelling and parenting behavior effects on offscpring alcohol and cigarette use. A growth curve analysis. J Subst Abuse 2000;12:287-310

28 Webster RA, Hunter M, Keats JA. Personality and sociodemographic influences on adolescents' substance use: a path analysis. Int J Addict 1994;29:941-56.

29 Wilks J, Callan VJ, Austin DA. Parent, peer and personal determinants of adolescent drinking. Br J Addict 1989;84:619-30.

30 Wills TA, Schreibman D, Benson G, et al. Impact of parental substance use on adolescents: a test of a mediational model. J Pediatric Psychol 1994;5:537-56.

31 Jacob T, Johnson S. Parenting influences on the development of alcohol abuse and dependence. Alcohol Health Res World 1997;21:204-9.

32 Foxcroft DR, Lowe G. Adolescent drinking behaviour and family socialization factors: a meta analysis. J Adol 1991;14:255-73.

33 Bahr SJ, Marcos AC, Maughan SL. Family, educational and peer influences on the alcohol use of female and male adolescents. J Stud Alcohol 1995;56:457-69.

34 Rose CD. Peer cluster theory and adolescent alcohol use: an explanation of alcohol use and a comparative analysis between two causal models. J Drug Educ 1999;29:205-15.

35 Windle M. Effect of parental drinking on adolescents. Alcohol Health Res World 1996:20:181-4.

36 Jessor R. Risk behavior in adolescence: a psychosocial framework for understanding and action. J Adol Health 1991;12:597-605.

37 Epstein JA, Botvin GJ, Baker E, et al. Impact of social influences and problem behavior on alcohol use among inner-city Hispanic and Black adolescents. J Stud Alcohol 1999;60:595-604.

38 Jessor R, Chase JA, Donovan JE. Psychosocial correlates of marijuana use and problem drinking in a national sample of adolescents. Am J Public Health 1980;70:604-13.

39 Wills TA, Vaccaro D, McNamara G. Novelty seeking, risk taking, and related constructs as predictors of adolescent substance use: an application of Cloninger's theory. J Subst Use 1994;6:1-20.

40 Silva PA, Stanton WR, eds. From child to adult. The Dunedin Multidisciplinary Health and Development Study. Auckland: Oxford University Press, 1996

41 Elley WB, Irving JC. Revised socio-economic index for New Zealand. New Zealand Journal of Educational Research 1976;11:25-56.

42 Elley WB, Irving JC. The Elley-Irving socio-economic index: 1981 census revision. New Zealand Journal of Educational Research 1985;20:115-28

43 Holahan CJ, Moos RH. The quality of social support: measure of family and work relationships. Br J Clin Psychol 1983;22:157-62.

44 Moos R, Moos B. Family environment scale test manual. California: Consulting Psychologists Press, 1986

45 Nada Raja S, McGee R, Stanton W. Perceived attachments to parents and peers and psychological well-being in adolescence. Youth Adol 1992;21:471-85.

46 Rosenberg M. Society and the adolescent self-image. Princeton, NJ: Princeton University Press, 1965

47 Rutter M, Tizard J, Whitmore K. Education, health and behaviour. London: Longman, 1970.

48 Stanton WR, Nada Raja S, Langley J. Stability in the structure of health locus of control among adolescents. Br J Clin Psychol 1995:34:279-87.

49 Wallston KA, Wallston BS, DeVellis R. Development of the Multidimensional Health Locus of Control (MHLC) Scales. Health Educ Monogr 1978;6:160-70.

50 Quay HC, Peterson DR. Manual for the revised behavior problem checklist. Coral Gables, FL: University of Miami, 1987.

51 Wechsler D. Manual of the Wechsler Intelligence Scale for children-revised. New York: Psychological Corp, 1974. 
52 Liang KY, Zeger SL. Longitudinal data analysis using Generalized Linear Models. Biometrika 1986;73:13-22.

53 Connolly G, Casswell S, StewartJ, et al. Drinking context and other influences on the drinking of 15 year old New Zealanders. Br J Addict 1992;87:1029-36.

54 Fitzgerald JL, Mulford HA. Alcohol consumption in lowa 1961 and 1979: a comparison of sales and survey estimates. J Stud Alcohol 1982;43:1171-89.

55 Campbell FA, Ramey CT. Effects of early intervention on intellectual and academic achievement: a follow-up study of children from low-income families. Child Devel 1994:65:684-98.

56 Caspi A, Harkeness AR, Moffitt TE, et al. Intellectual performance: continuity and change. In: Silva PA, Stanton WR, eds. From child to adult. The Dunedin Multidisciplinary Health and Development Study. Auckland: Oxford University Press, 1996.

57 Scarr S, McCartney K. How people make their own environments: a theory of genotype-environment effects. Child Devel 1983;54:424-35.

58 Martin SL, Ramey CT, Ramey S. The prevention of intellectual impairment in children of impoverished families: findings of a randomized trial of educational day care. Am J Public Health 1990;80:844-7.

59 Barnett WS. Long-term cognitive and academic effects of early childhood education on children in poverty. Prev Med 1998:27:204-7.

60 Zoritch B, Roberts I, Oackley A. The health and welfare effects of day-care: a systematic review of randomised controlled trials. Soc Sci Med 1998;47:317-27.

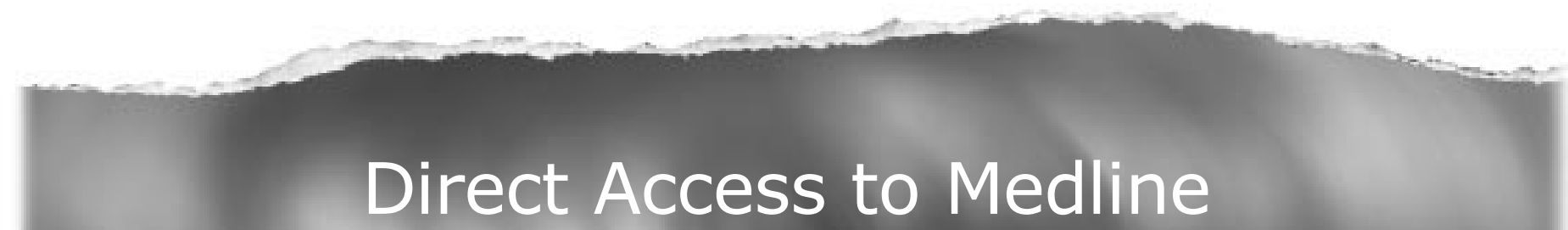

Medline

Link to Medline from the homepage and get straight into the National Library of Medicine's premier bibliographic database. Medline allows you to search across 9 million records of bibliographic citations and author abstracts from approximately 3,900 current biomedical journals.

www.jech.com 